\title{
INTERPRETAÇÃO AMBIENTAL DO GEOPATRIMÔNIO DO PARQUE ESTADUAL DO IBITIPOCA/MG POR MEIO DE PAINÉIS: ALGUMAS ORIENTAÇÕES
}

\author{
Lilian Carla Moreira Bento ${ }^{1}$ \\ Sílvio Carlos Rodrigues
}

\begin{abstract}
Resumo: A interpretação ambiental busca o entendimento da natureza através de diferentes recursos, tais como os painéis. Em pesquisas anteriores, foi diagnosticada a demanda por esse tipo de recurso no Parque Estadual do Ibitipoca/MG (PEI) e, como não existe nenhum programa educativo voltado especificamente para o geopatrimônio, essa pesquisa se propôs a apresentar algumas orientações para a elaboração de painéis a serem afixados em geossítios de grande valor didático e turístico. Tendo como ponto de partida os resultados de uma avaliação numérica dos geossítios desse parque, realizada em outra pesquisa, chegou-se a conclusão de que existem quatro pontos ideais para a colocação dos painéis, sendo estes: Pico do Pião, Gruta dos Coelhos, Cachoeira dos Macacos e Prainha. A implantação destes painéis, a cargo da direção do parque, será de grande relevância no processo de geoconservação, promovendo a valorização e divulgação do geopatrimônio que este parque apresenta.
\end{abstract}

Palavas-Chave: Interpretação. Geodiversidade. Unidades de conservação.

\section{ENVIRONMENTAL INTERPRETATION OF IBITIPOCA/MG STATE PARK GEOPATRIMONY BY MEANS OF PANELS: SOME GUIDELINES}

\begin{abstract}
Environmental interpretation seeks to understand nature through different resources, such as panels. In previous research, the demand for this type of resource was diagnosed in the Ibitipoca State Park/MG (PEI) and, as there is no educational program focused specifically on geopatrimony, this research proposed to present some guidelines for the elaboration of panels, are to be affixed to geosites of great didactic and tourist value. Taking as a starting point the results of a numerical evaluation of the geosites of this park, carried out in another research, it was concluded that there are four ideal points for the placement of the panels: Pico do Pião, Gruta dos Coelhos, Cachoeira dos Macacos and Prainha. The implementation of these panels, in charge of the park management, will be of great importance in the geoconservation process, promoting the valorization and dissemination of the geopatrimony.
\end{abstract}

Keywords: Interpretation. Geodiversity. Conservation units.

\footnotetext{
${ }^{1}$ Prof. Dr. Curso de Geografia da FACIP-UFU. Iiliancmb@ufu.br

2 Instituto de Geografia - Universidade Federal de Uberlândia. silgel@ufu.br
} 


\section{INTRODUÇÃO}

Em grande parte das unidades de conservação brasileiras, o geopatrimônio é a base para a configuração paisagística, todavia, o que se percebe é a sua depreciação, com poucas iniciativas voltadas à sua valorização e divulgação (PIEKARZ; MANOSSO; LICCARDO, 2009). E o geopatrimônio, como Martinez et al. (2008) explicam, é parte do patrimônio natural que deve ser conservado, sendo que o mínimo a se fazer é buscar uma conservação integral do meio natural, já que no registro geológico está escrito o livro de nossa própria existência, uma herança para as gerações futuras e da qual dependemos para sobreviver.

O Parque Estadual do Ibitipoca, localizado na Zona da Mata, em Minas Gerais (Brasil) - (Figura 1), não foge a essa realidade. É uma unidade de conservação de grande beleza cênica e que tem o geopatrimônio como suporte para a existência dos atrativos ofertados ao público, como cavernas, quedas d'água, praias fluviais, entre outros.

Figura 1: Localização da área de estudo

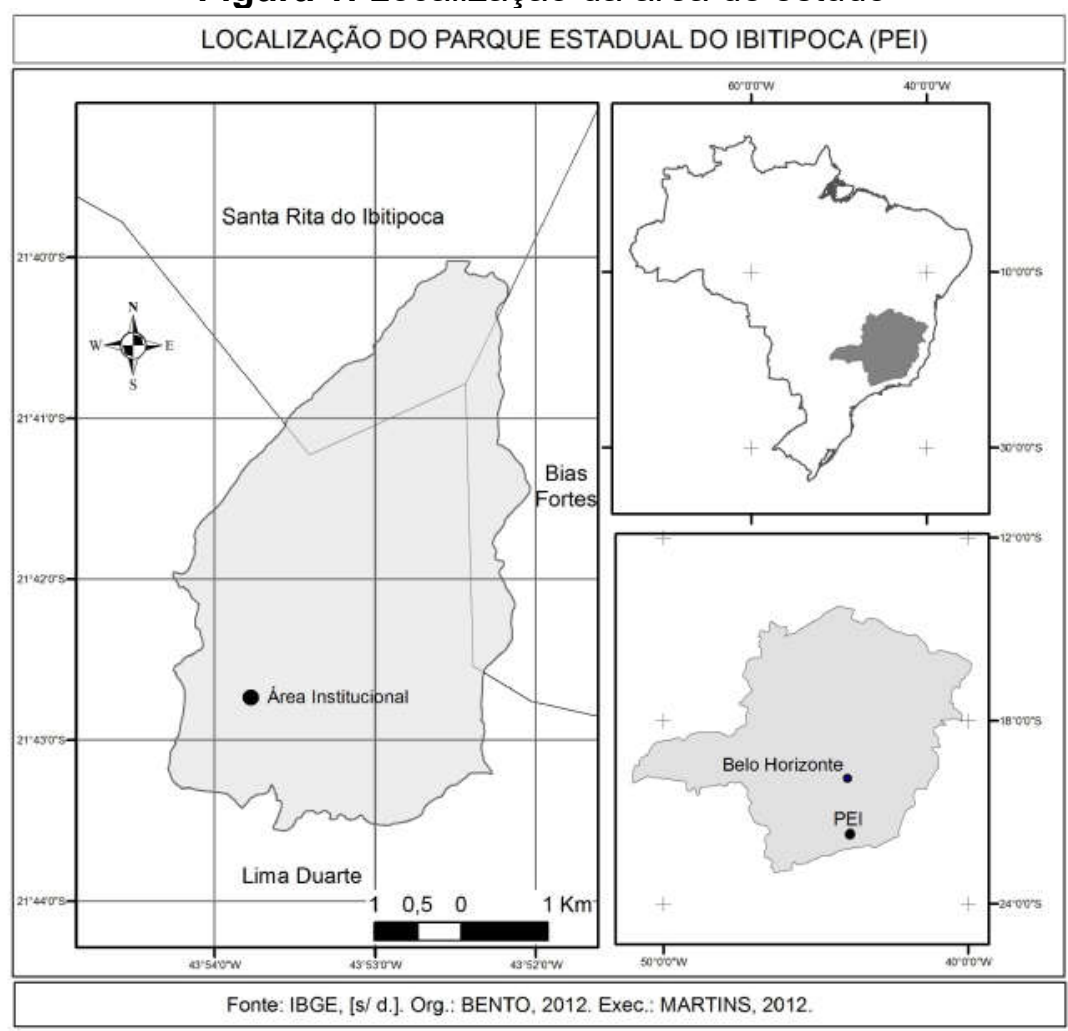

Apesar disso e de possuir infraestrutura turística, com sinalização reguladora, informativa e indicativa, não existem placas interpretativas (nem sobre a Biodiversidade e muito menos da Geodiversidade), esta sendo, inclusive, uma das demandas dos visitantes, segundo pesquisa de Simiqueli (2008). Isso significa que as trilhas do parque, as quais podem ser feitas autoguiadas, estão sendo subutilizadas, havendo o desperdício de oportunidades de aprendizado. Destaca-se que essa demanda não é inerente apenas a este parque, Verdecchia (2009) em uma 
pesquisa em áreas protegidas na Venezuela, identificou que $70 \%$ dos visitantes, apesar da motivação principal ser o descanso e recreação, tal como no PEI, sentem falta de sinalização interpretativa, informações e guias.

Considerando as demandas existentes no $\mathrm{PEI}$, entende-se que a interpretação ambiental pode ser encarada como um instrumento voltado a transformar essa realidade, direcionando o olhar dos visitantes para uma parte da natureza que vem sendo negligenciada, revelando-os sobre a importância do geopatrimônio. Diante disso, o objetivo deste artigo é apresentar algumas orientações para a elaboração de painéis interpretativos para o Parque Estadual do Ibitipoca, visando preencher uma lacuna do ponto de vista do conhecimento do seu geopatrimônio, oportunizando sua valorização e divulgação.

\section{METODOLOGIA}

A proposição de painéis interpretativos deve fazer parte de uma investigação mais ampla e que envolve, antes, algumas etapas fundamentais, a saber: o levantamento e caracterização dos geossítios e a avaliação numérica destes geossítios, de forma a se direcionar quais os locais mais propícios para tal.

A partir do resultado da avaliação numérica (BENTO; RODRIGUES, 2014), chegou-se aos geossítios a serem interpretados, etapa alvo deste artigo, sendo de grande relevância a análise de obras que focassem a temática da interpretação, principalmente, aquelas voltadas à elaboração de painéis, uma vez que, dada as características do parque e as demandas dos visitantes, foi o meio escolhido para a interpretação do geopatrimônio.

Usou-se como referencial principal as obras de Fonseca (2010), Murta; Albano (2002), Pacheco (2012), Projeto Doces Matas (2002), Tilden (1957) e Vasconcelos (1998) e, entre esses autores, é consensual a necessidade de elaboração de um plano interpretativo no qual deve constar o tema, objetivos e público-alvo (Figura 2).

Figura 2: Fluxograma metodológico simplificado
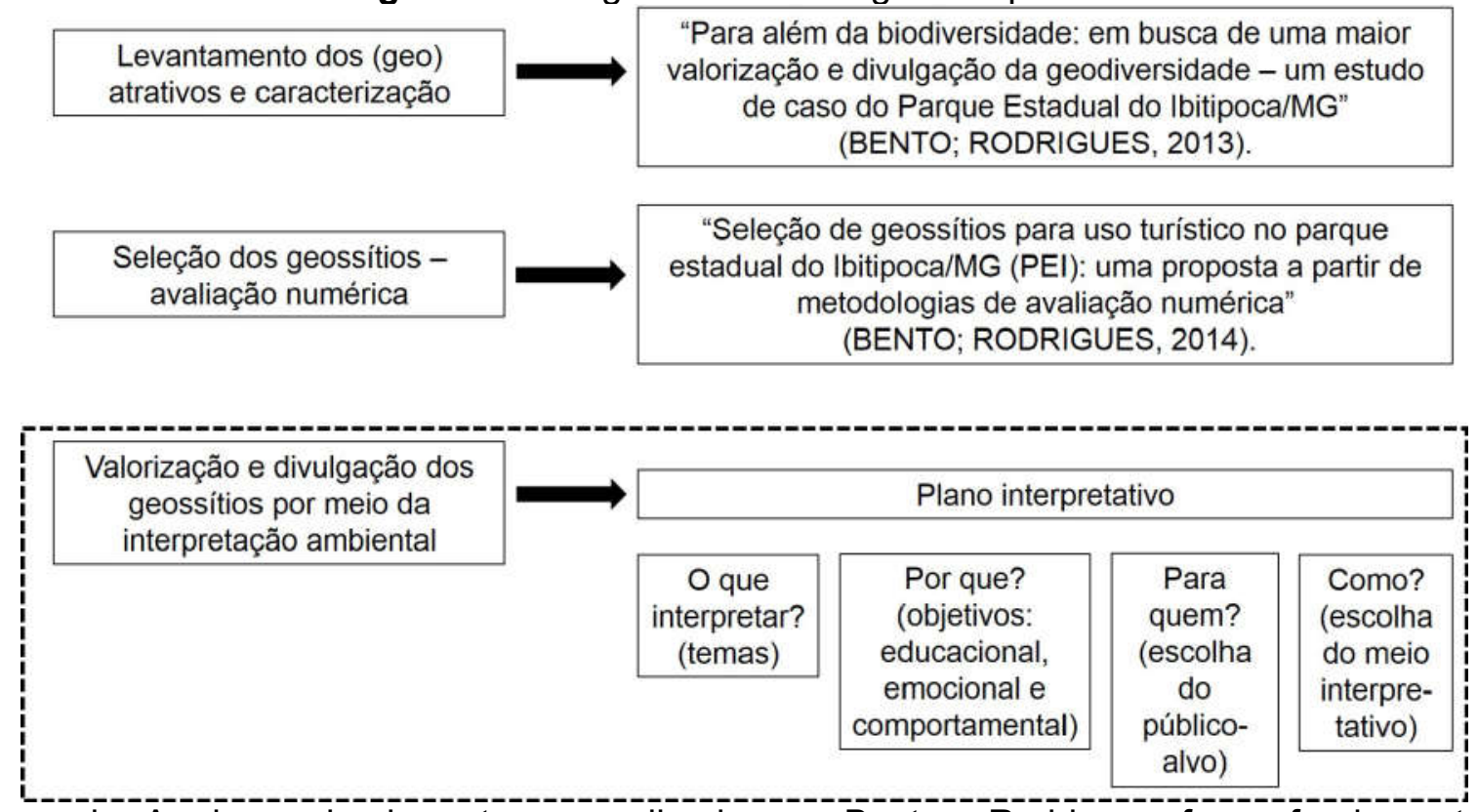

Legenda: As duas primeiras etapas, realizadas por Bento e Rodrigues, foram fundamentais para apontar quais os geossítios são mais propícios para a interpretação ambiental e, na 
parte hachurada, destaca-se a etapa apresentada neste artigo e que se pautou na elaboração de um plano interpretativo para a proposição dos painéis. Autoria própria, 2019.

Com relação ao plano interpretativo, o primeiro questionamento (o que interpretar?) se pautou no resultado da etapa de seleção dos geossítios mediante a avaliação numérica, tendo-se o cuidado de privilegiar sítios com temáticas diferentes, possibilitando um entendimento mais amplo por parte dos visitantes, neste caso: cavernas, quedas d'água, praias fluviais e mirantes. O segundo (por que?), se baseou em três objetivos: educacional (o que se quer que os visitantes saibam), emocional (o que se quer que os visitantes sintam) e comportamental (o que se quer que os visitantes façam), cada objetivo sendo respondido tendo em vista as quatro categorias temáticas escolhidas. Em, (para quem?), ou seja, na escolha do público-alvo, optou-se em considerar todos os visitantes do parque, um grupo bastante heterogêneo. E, por fim, no item (como?), a escolha foi pelos painéis interpretativos em virtude das características da área de estudo, na qual o acesso aos atrativos pode ser feito por trilhas autoguiadas e uma das demandas dos turistas diz respeito à necessidade de disponibilizar mais informações ao longo das mesmas.

Tendo como ponto de partida esse plano, foram propostos os painéis para cada ponto interpretativo, além de mais um a ser colocado no Centro de Visitantes, chamando a atenção dos mesmos para os demais painéis e qual a sua finalidade. As explicações dos painéis tiveram como pressuposto alguns questionamentos relacionados com esses eixos, tais como: Por que o parque está numa área tão elevada? De onde veio toda essa areia? Qual a explicação para a existência de tantas cavernas? O que explica a heterogeneidade do solo, rocha e vegetação encontrados no parque?

\section{ESTADO DA ARTE}

\section{INTERPRETAÇÃO AMBIENTAL: ALGUNS CONCEITOS E IMPORTÂNCIA}

No Brasil, uma das obras que trata com mais detalhe a temática da interpretação ambiental foi escrita por Murta e Albano em 2002. Segundo as autoras supracitadas, a interpretação ambiental teve início, informalmente, nos parques norte-americanos, buscando a sensibilização dos turistas; porém, foi Freeman Tilden quem primeiro escreveu um livro sobre esse assunto "Interpreting our heritage", em 1957.

Tilden definiu interpretação ambiental como "[...] an educational activity which aims to reveal meanings and relationships through the use of original objects, by firsthand experience, and by illustrative media, rather than simply to communicate factual information" (1957, p. 8). Posteriormente, ele atualizou sua definição e, ao invés de atividade educativa, mudou para atividade recreativa, sendo que o propósito maior da interpretação é transmitir uma mensagem para o visitante, não apenas informação e muito menos de maneira formal, a mensagem a ser transmitida deve ter algum significado e ser provocativa, induzindo-o a querer saber mais.

Após o conceito de Freeman Tilden foram elaborados outros mundo afora, como o da National Countryside Commission, Inglaterra, que ressalta o papel da interpretação como um processo de desenvolver o interesse e o prazer do visitante por uma área, através de explicações de suas características e inter-relações (MURTA; ALBANO, 2002). 
$\mathrm{Na}$ década de 1970 sobressaem dois conceitos, um de autoria de Don Aldridge e outro de Sharpe. O primeiro reforça a importância da inserção do homem no meio ambiente, despertando nele o desejo de contribuir para a conservação do meio ambiente. Já a definição de Sharpe se parece mais com a de Tilden, porém, ele considera a interpretação ambiental como um serviço a ser ofertado pelas áreas protegidas ou de recreação, devendo conectar os visitantes com os recursos (PROJETO DOCES MATAS, 2002).

Mais recentemente, em 1992, Ham, dirigente e professor do Centro Internacional de Formação da Universidade de Idaho College of Natural Resources (EUA), autor de inúmeras publicações na temática, reforça que a interpretação ambiental envolve a tradução de uma ciência em termos e ideias compreensíveis pelo público leigo, no entanto, através de uma maneira divertida e interessante (PACHECO, 2012; PROJETO DOCES MATAS, 2002;).

Atualmente existem muitas definições para interpretação ambiental, inclusive, a palavra interpretação possui vários significados, sendo que a maioria tem como base os pressupostos de Tilden, fazendo com que existam pontos em comum, a saber: a) é uma forma de comunicação e tradução dos lugares, b्) busca o entendimento através da sensibilização e c) seu objetivo maior é compartilhar responsabilidades no que diz respeito ao processo de conservação (DELGADO, 2000; FARIA; PIRES, 2007; FOLMANN; PINTO; GUIMARÃES, 2010; HAM, 2007; IKEMOTO, 2008; 2007 IKEMOTO; MORAES; COSTA, 2009; MACHADO, 2008; ; MENEGHINI; GUERRA, 2008; RODRIGUES, 2008; MIRANDA; 2008; MINISTÉRIO DO MEIO AMBIENTE - MMA, 2006; MINISTÉRIO DO TURISMO - MT, 2010; MOREIRA, 2012; MURTA; ALBANO, 2002; URQUÍ; MARTINEZ; VALSERO, 2007).

Murta e Goodey (2002) explicam que no Brasil a interpretação ambiental é mais recente e sua divulgação teve início a partir da década de 1990, buscando a valorização da experiência do visitante. Já a interpretação, em específico, do geopatrimônio compreende as etapas do processo de geoconservação: valorização e divulgação (BRILHA, 2005) as quais, segundo Urquí, Martinez e Valsero (2007) compreendem o leque de ações voltadas a transmitir aos visitantes o seu valor, objetivando promover seu entendimento e estimular atitudes voltadas à conservação da natureza.

A interpretação do geopatrimônio vai ao encontro dos objetivos do geoturismo em fazer com que os turistas entendam essa vertente abiótica da natureza, podendo ser considerada, segundo Rodrigues e Carvalho (2009), como a base para uma estratégia de geoturismo, a qual prepara os lugares com ferramentas que possibilitam usufruir melhor da geologia e geomorfologia locais.

Além de contribuir com o geoturismo, a interpretação ambiental oportuniza outros benefícios. O Ministério do Turismo (2010) destaca o que denomina de Agregação de atividades, ou seja, é uma ferramenta capaz de estimular a ampliação da permanência do visitante no destino, uma vez que propiciará o desenvolvimento de outras atividades, a partir do geoturismo. Além disso, possui um efeito multiplicador ao possibilitar um aprendizado transformador e criativo, acabando por contribuir para a evolução da incorporação de novos padrões atitudinais e comportamentais, os quais, inicialmente restringem ao indivíduo, mas depois podem influenciar grupos receptivos a estas mudanças (GUIMARÃES, 2007).

Miranda (2008) divide os benefícios da interpretação ambiental em três âmbitos: i) para o lugar: contribui para a conservação do sítio; ii) para as instituições: melhora a gestão e aproveitamento recreativo e educativo e iii) para as pessoas: 
enriquece a visita, dotando-a de significados, contribuindo para a adoção de atitudes de respeito para com a natureza.

Giacomo (2006, p. 31) salienta essa última característica, afirmando que a interpretação ambiental é

[...] um instrumento essencial à conservação e gerenciamento do patrimônio. É uma atividade que ao acrescentar valor ou ao realçar a experiência vivida em um lugar, estimula a apreciação ambiental, induzindo atitudes de respeito e proteção, além de promover entretenimento para usuários e visitantes. $E$, principalmente, populariza o conhecimento ambiental e busca sensibilizar as pessoas para que elas tenham atitudes preservacionistas em relação ao patrimônio.

Essa citação vai ao encontro de uma máxima muito divulgada por Tilden (1957, p. 38), "through interpretation, understanding; through understanding, appreciation; through appreciation, protection", mostrando que a interpretação induz sentimentos como compreensão e apreciação, fundamentais ao processo de proteção dos lugares.

Apesar do seu viés educativo, a interpretação não deve ser confundida com educação ambiental. Enquanto esta última é um processo educativo, contínuo e demorado, podendo acontecer em ambientes formais e não formais, a interpretação, ao contrário, é uma atividade pontual e local voltada à sensibilização do visitante, através de uma tradução das paisagens, pois os ambientes naturais não falam por si. Por isso, ela deve ser encarada apenas como um instrumento da educação ambiental, visto que proporciona conhecimento sobre alguma coisa e visa à mudança de comportamentos considerados ambientalmente incorretos (DELGADO, 2000; IKEMOTO; MORAES; COSTA, 2009; MOREIRA, 2011; VASCONCELOS, 2006; MOREIRA; BIGARELLA, 2008; SILVA et al., 2006).

Em virtude da importância do geopatrimônio é premente a realização de ações voltadas ao seu entendimento por um público em geral, tal como se propõe a fazer a interpretação ambiental. Não é difícil encontrar diversos pesquisadores empenhados nessa temática, tais como Fonseca (2010), Forte (2008), Machado (2008), Mansur (2010), Moreira (2008), Pacheco (2012), Pereira (2006), Rodrigues (2008), entre muitas outras.

Projetos relacionados à interpretação ambiental também estão demonstrando êxito no Brasil. O projeto "Caminhos geológicos", criado em 2001 pelo Departamento de Recursos Minerais - DRM/RJ é um exemplo de sucesso e, de acordo com Mansur e Nascimento (2007), seu objetivo central é promover a difusão do conhecimento geológico do Estado do Rio de Janeiro, visando à preservação dos seus monumentos geológicos mediante a instalação de painéis interpretativos, num total de 102 já instalados em todo o Estado.

\section{DESAFIOS DA INTERPRETAÇÃO DO GEOPATRIMÔNIO}

Como precursor da interpretação ambiental, Tilden (1957) foi o primeiro a delinear alguns princípios e teorias sobre esse tema. São seis os princípios estabelecidos; entretanto, ele próprio os resume em um só: o amor. O interesse em se entender algo surge primeiro de algum tipo de sentimento, é preciso haver empatia e, para isso, deve existir um conhecimento prévio, a temática deve estar relacionada com ele. Esses seis princípios são detalhados a seguir: 
1- A interpretação precisa ser significativa para os visitantes, dessa forma, a mensagem deve ser contextualizada, fazendo com que estes, em algum momento, se identifiquem com o que está sendo abordado.

2- A interpretação se baseia em informações sobre determinado lugar; porém, não deve se limitar a isso, uma vez que seu objetivo é sensibilizar o visitante, devendo estimular a sua curiosidade e interesse.

3- A interpretação é uma arte que combina muitas artes para explicar, isto é, para conseguir transmitir uma mensagem clara e, ao mesmo tempo, atraente, precisa ser diversificada, sendo expressa em diferentes meios interpretativos.

4- O propósito da interpretação é direcionar o olhar dos visitantes para determinados aspectos que passariam despercebidos e/ou incompreendidos, mas através de mensagens persuasivas e que os façam refletir.

5- Uma mensagem interpretativa deve levar em conta as inter-relações existentes, sendo trabalhada de forma holística, fazendo com que os visitantes compreendam e se sintam parte do meio ambiente.

6- Para que a interpretação consiga transmitir uma mensagem clara, atraente e contextualizada o conhecimento do público-alvo é essencial.

Em síntese, esses princípios evocam os desafios da interpretação, relacionados ao público-alvo e a mensagem. Referente ao público, é de suma importância conhecer o seu perfil, seus anseios e expectativas, para conseguir fazer uma interpretação contextualizada e, ao mesmo tempo, interessante e com significado. Porém, Miranda (2008) explica que essa não é uma tarefa fácil em áreas protegidas, porque o público é muito heterogêneo e, além disso, está gozando de seu tempo livre, sem ter obrigação de participar de qualquer atividade interpretativa.

No caso da mensagem, ela tem de ser bastante persuasiva, capaz de provocar o público, de forma que as pessoas tenham interesse em participar das atividades e refletir, despertando nelas um desejo de aprender e, quem sabe, contribuir no processo de conservação (PACHECO, 2012). Ham (2011, p. 19) explica que a provocação deve ser a característica principal da interpretação, somente assim as pessoas são persuadidas a pensar, sentir ou agir de uma determinada maneira:

[...] cuando somos provocados por la interpretación, nos asombramos, reflexionamos acerca de lá cuestión planteada y, a veces, consideramos nuevas y sorprendentes posibilidades acerca de un lugar, un objeto o un concepto. Es decir, pensamos. La interpretación que consigue provocar la audiência es convicente. Em ocasiones puede dar como resultado la implantación de nuevas convicciones acerca de aquello que es interpretado, o bien que algumas creencias (convicciones) existentes cambien o sean sustituidas.

Miranda (2008) e Ham (2011) acrescentam que num curto período de tempo é difícil que os visitantes estabeleçam algum tipo de vínculo afetivo com o lugar. Dessa forma, independente do tipo de meio interpretativo utilizado, a mensagem deve causar impacto e ser significativa, provocando o pensamento dos visitantes e fazendo com que, em outros momentos, tenham o interesse de saber mais sobre o assunto.

Uma primeira característica de uma mensagem persuasiva é que deve ser clara o bastante para ser entendida por um público em geral. Quanto à interpretação 
do geopatrimônio, a dificuldade é ainda maior, pela quantidade de termos técnicos existentes (COSTA, 2006; DIAS et al., 2003; FORTE, 2008; HOSE, 2011; MARAGLIANO, 2010; MURTA; ALBANO, 2002; OLIVEIRA, 2010; RODRIGUES, 2008; PACHECO, 2012; VASCONCELOS, 1998;). Nesse caso, Robinson (1998, p. 152) faz um apelo aos profissionais das geociências, dizendo que sua maior missão reside justamente no fato de tornar sua ciência em termos mais simples para serem transmitidos à população leiga: "[...] need to turn their wisdom into simple terms laced with whataver enthusiasm they can transfer. To turn science into simple statement is no betrayal, it's a mission".

Gutiérrez-Marco (2005) explica que a dificuldade da popularização das geociências reside justamente nesse problema da linguagem, sendo preciso que sua divulgação seja realizada de forma mais interessante e clara para o público leigo, tal como se propõe a fazer a interpretação ambiental.

Ao elaborar uma mensagem para a interpretação é preciso, mais uma vez, lembrar-se que o público é não cativo e, a maioria, busca a diversão e o descanso, sendo necessário conciliar educação e recreação, tal como lembra Reynard (2008, p. 228), "the challenge is, therefore, to develop tools that combine these two aspects, leisure and education, to disseminate knowledge on geosciences towards a large public".

\section{RESULTADOS E DISCUSSÃO}

Com base na metodologia apresentada foi possível elaborar o plano interpretativo para o PEI (Figura 3):

Figura 3: Plano interpretativo para o geopatrimônio do Parque Estadual do Ibitipoca 


\begin{tabular}{|c|c|c|c|c|}
\hline Etapa & Gruta dos Coelhos & Prainha & $\begin{array}{l}\text { Cachoeira dos } \\
\text { Macacos }\end{array}$ & Pico do Pião \\
\hline $\begin{array}{l}\text { O que interpretar? } \\
\text { (escolha do tema } \\
\text { principal) }\end{array}$ & $\begin{array}{l}\text { Processo de } \\
\text { dissoluçâo em rocha } \\
\text { metamórfica. }\end{array}$ & $\begin{array}{l}\text { Processo de erosão e } \\
\text { deposição fluvial. }\end{array}$ & $\begin{array}{l}\text { Influência do } \\
\text { tectonismo ro na } \\
\text { formação de quedas } \\
\text { d'água. }\end{array}$ & $\begin{array}{l}\text { A formação do } \\
\text { relevo, destacando a } \\
\text { dinâmica terrestre. }\end{array}$ \\
\hline $\begin{array}{l}\text { Por quẽ? } \\
\text { (objetivos) } \\
1 \quad \text { que se } \\
\text { pretende que eles } \\
\text { conheçam? }\end{array}$ & $\begin{array}{l}\text { Que o quartzito } \\
\text { também pode ser } \\
\text { dissolvido, através de } \\
\text { seus pontos de } \\
\text { fraqueza, formando } \\
\text { grutas, com grande } \\
\text { riqueza de detalhes. } \\
\text { como os } \\
\text { espeleotemas. Além } \\
\text { disso, que são locais } \\
\text { únicos e de grande } \\
\text { importância para a } \\
\text { fatma local. }\end{array}$ & $\begin{array}{l}\text { Que ao longo de rios } \\
\text { também podem ser } \\
\text { depositados bancos } \\
\text { de areias. formando } \\
\text { praias. }\end{array}$ & $\begin{array}{l}\text { Que existem } \\
\text { explicações variadas } \\
\text { para a formação das } \\
\text { quedas, sendo que o } \\
\text { tectonismo é a mais } \\
\text { comum. A ação da } \\
\text { água, geralmente. é } \\
\text { mais na evolução da } \\
\text { queda. }\end{array}$ & $\begin{array}{l}\text { Que a Terra é } \\
\text { dinâmica e sofre } \\
\text { soerguimentos e, ao } \\
\text { mesmo, processos } \\
\text { erosivos diferenciais, } \\
\text { ocasionando o seu } \\
\text { rebaixamento. } \\
\text { Ressaltar que o } \\
\text { homem é unu agente } \\
\text { geomorfológico e. } \\
\text { como tal, também } \\
\text { impacta a paisagem, } \\
\text { de forma positiva ou } \\
\text { negativa. }\end{array}$ \\
\hline $\begin{array}{l}2 \quad 0 \quad \text { que re } \\
\text { pretende que eles } \\
\text { sintam? }\end{array}$ & \multicolumn{4}{|c|}{$\begin{array}{l}\text { - Curiosidade em conhecer os demais pontos de temas interpretativos semelhantes. } \\
\text { observando as particularidades de cada um. } \\
\text { - Admiração e respeito pelo papel da Natureza em cada detalhe, no equilibrio e na dinâmica } \\
\text { constante que existe. } \\
\text { - Responsabilidade e necessidade de conservar a bio e geodiversidade. }\end{array}$} \\
\hline $\begin{array}{l}\text { Quem? (público- } \\
\text { alvo) }\end{array}$ & \multicolumn{4}{|c|}{$\begin{array}{l}\text { São os turistas que visitam o parque. A maioria tem curso superior, estão em grupos de } 2 \text { a } 5 \\
\text { pessoas, tem idade média de } 24 \text { anos e o motivo da visita é o lazer e o descanso. }\end{array}$} \\
\hline $\begin{array}{l}\text { Como, quando e } \\
\text { onde? (seleçâo dos } \\
\text { meios } \\
\text { interpretativos) }\end{array}$ & \multicolumn{4}{|c|}{$\begin{array}{l}\text { - O acesso aos atrativos pode ser feito por trilhas autoguiadas e uma das demandas dos } \\
\text { turistas diz respeito à necessidade de disponibilizar mais informaçôes ao longo das mesmas, } \\
\text { inserindo explicaçres nas placas do parque. } \\
\text { - Dada essa realidade. o meio interpretativo selecionado foram as placas e o local } \\
\text { corresponde aos pontos interpretativos de maior valor obtidos na avaliação numérica. }\end{array}$} \\
\hline
\end{tabular}

Com relação ao que deve ser abordado em cada painel, o resultado está de acordo com o plano interpretativo, sendo assim, a partir dos tópicos do plano interpretativo, o que interpretar e o que se pretende que os visitantes conheçam, tem-se como sugestão as seguintes explicações:

- Processo de erosão e deposição fluvial: existem praias fluviais ao longo dos principais cursos d'água e isso está associado aos processos de erosão e deposição. A Prainha, geossítio selecionado para fixação do painel, está localizado nas coordenadas 23K 0614466 UTM 7598968 e corresponde a uma praia natural formada pela deposição dos sedimentos sílico-argilosos transportados pelo rio do Salto. Estes sedimentos foram erodidos das encostas e, devido ao grande potencial hidráulico por conta da altitude da Serra do Ibitipoca, carregados e depositados ao longo dos declives mais suaves. Em outras partes do parque é possível encontrar esses sedimentos arenosos, em virtude do processo de intemperização da rocha predominante no parque, os quartzitos. - (Figura 4).

Figura 4: Aspectos a serem abordados no painel interpretativo da temática praia fluvial 

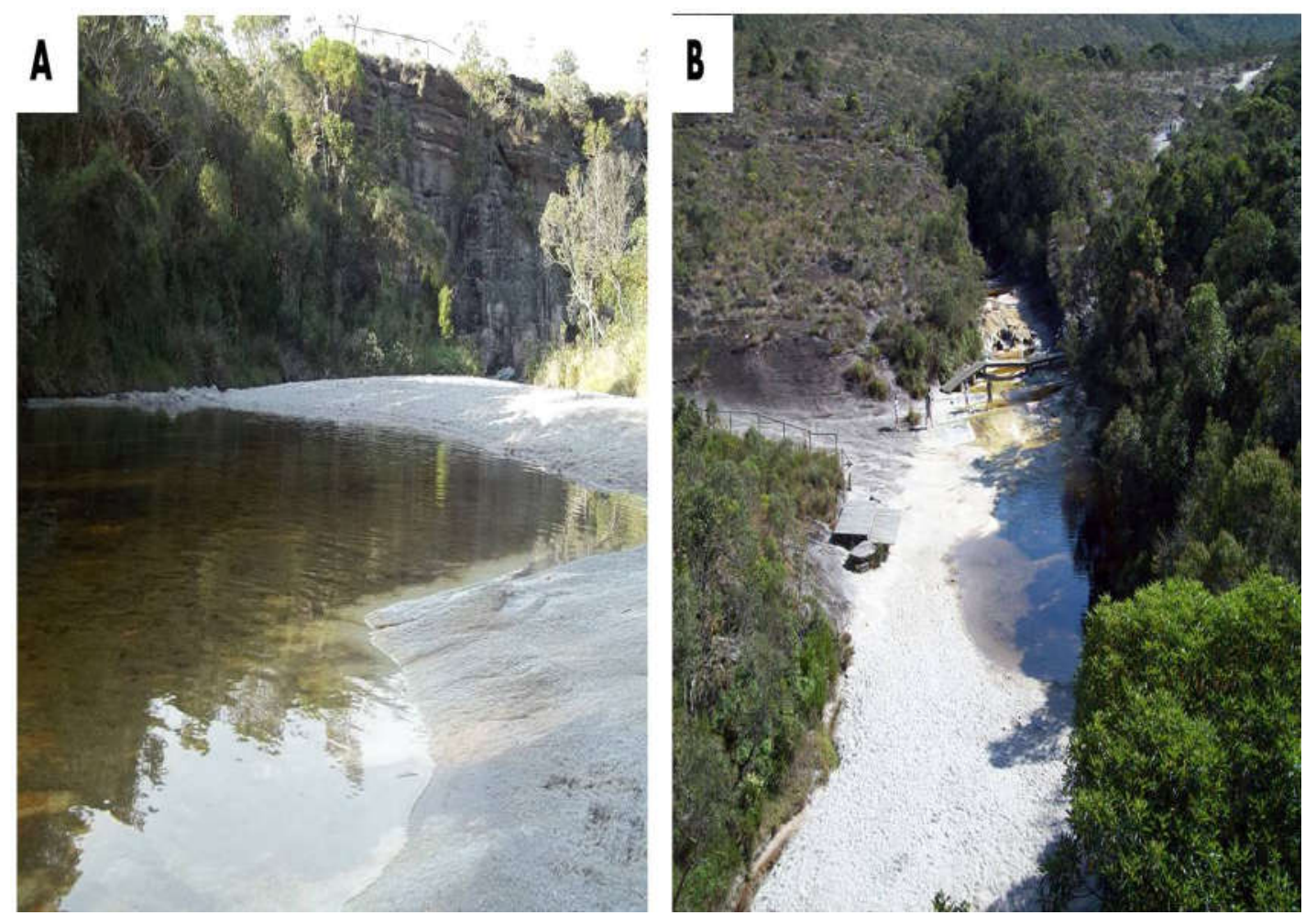

Legenda: A e B - o rio do Salto ao longo do seu percurso erode as suas margens, transportando e depositando os sedimentos arenosos (por conta de ser o quartzito a rocha mais abundante no local) em alguns pontos de menor declive, formando as praias fluviais encontradas ao longo do parque, neste caso, a Prainha. Autoria própria, 2015.

- Formação de cavernas em rochas quartzíticas: existem muitas cavernas no interior do parque e sua formação está associada ao processo de dissolução do quartzo e sua evolução a partir dos canalículos semelhantes aos pipes. Deve-se salientar a existência de microfeições, os espeleotemas, no intuito de aguçar o olhar dos turistas, levando-os a querer conhecer as demais cavernas para encontrar esses adornos naturais. Buscando uma visão integrada da natureza é importante evidenciar esses locais como habitat para alguns tipos de animais, muitos deles endêmicos, de modo que os turistas se sintam estimulados a vê-los. O local indicado para colocação do painel foi a Gruta dos Coelhos, localizada nas coordenadas 23K 0614224 UTM 7598810 - (Figura 5).

Figura 5: Aspectos a serem abordados no painel interpretativo da temática cavernas 

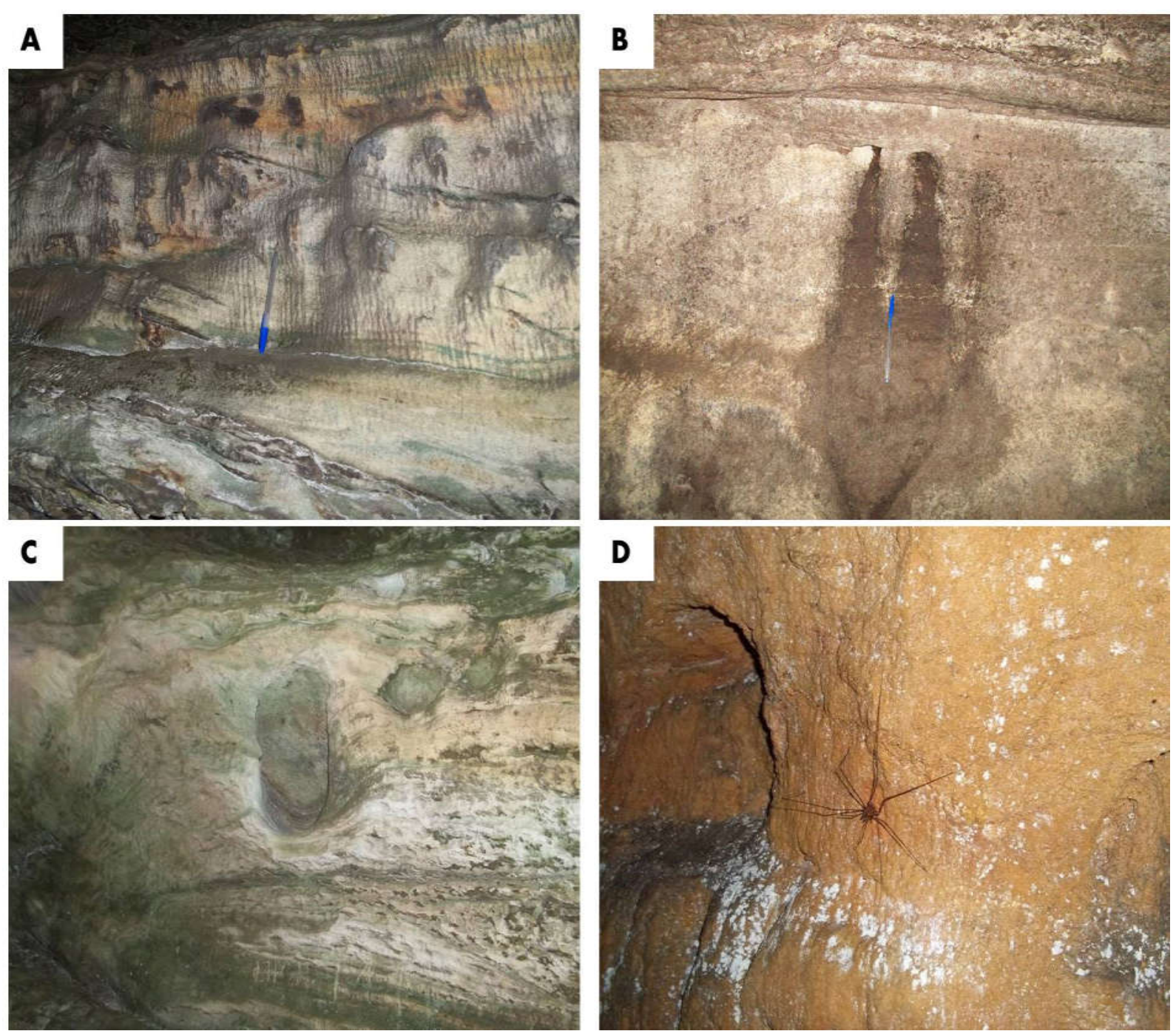

Legenda: A- Caneluras formadas pelo escorrimento da água, B- Canalículos do tipo pipes, C- Canalículos aumentados, expressando o intemperismo químico presente, bem como processo de dissolução da rocha e D- Exemplar de opilião (Opiliones) encontrado nas cavernas do parque. Autoria própria, 2015.

- Influência do tectonismo na formação de quedas d'água: apesar das quedas d'água serem muito frequentadas pelos turistas que visitam o parque, poucos sabem como esses locais foram formados. Nesse sentido, é necessário explicar sua formação e evolução a partir do tectonismo e ação geológica da água, bem como realçar a existência de microfeições ao longo do curso d'água (marmitas). Além disso, sendo um dos pontos mais baixos do relevo, deve-se levar o turista a refletir sobre as interações existentes entre os aspectos naturais, tendo a topografia como referência. A Cachoeira dos Macacos está localizada nas coordenadas 23K 0614427 UTM 7598194 - (Figura 6).

Figura 6: Aspectos a serem abordados no painel interpretativo da temática quedas d'água 

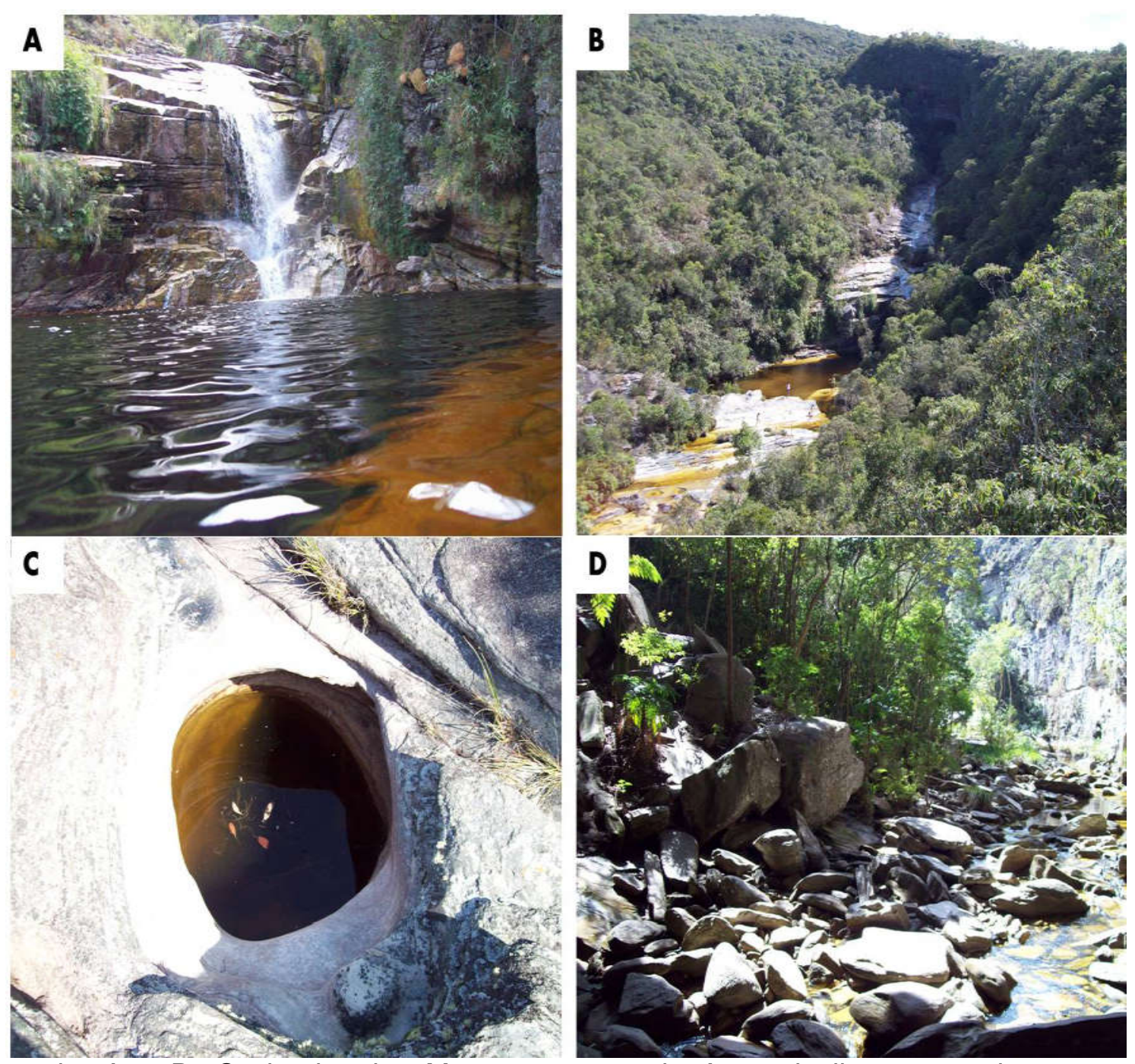

Legenda: A e B- Cachoeira dos Macacos: a cor da água sinaliza para a interação da geodiversidade com a biodiversidade a partir da presença das matas (ciliar e grande) que geram matéria-orgânica que desagua nos cursos d'água, C- Feição de erosão conhecida como marmita, formada a partir do turbilhonamento da água carregada de sedimentos e CGrandes blocos de rochas transportados pela água no período de grandes chuvas. Autoria própria, 2015.

- A formação do relevo, destacando a dinâmica terrestre: o parque se destaca topograficamente das áreas vizinhas, o que está associado com a evolução geológica a que a região foi submetida, sofrendo deformações tectônicas ao longo do tempo geológico. Além disso, a rocha predominante no parque, quartzito, é mais resistente que o xisto e o gnaisse encontrado nos arredores e interior do mesmo, havendo um processo de erosão diferencial. Primordial indicar o papel do homem como um agente modificador do relevo, induzindo os turistas a pensarem nos impactos das atividades humanas. O geossítio escolhido é o Pico do Pião, localizado nas coordenadas 23K 0616792 UTM 7599326 - (Figura 7).

Figura 7: Aspectos a serem abordados no painel interpretativo da temática áreas panorâmicas 

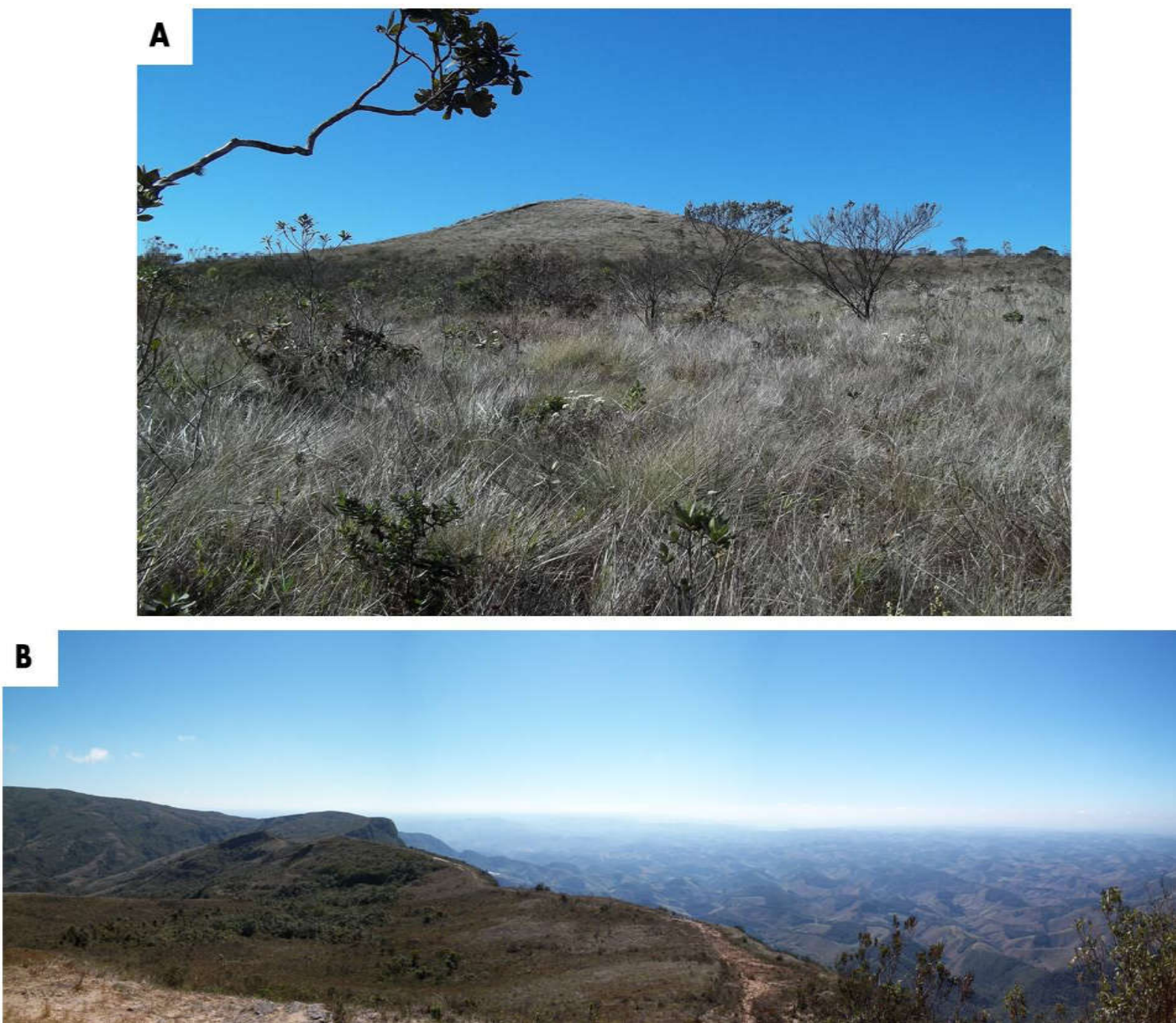

Legenda: A- Vista do Pico do Pião e da vegetação encontrada na área refletindo as interações entre a geodiversidade e biodiversidade e B- Vista a partir do Pico do Pião, sendo possível perceber o grande desnível topográfico do parque e das áreas vizinhas, onde são encontradas as formas de relevo conhecidas como mares de morro, sinalizando para o processo de erosão diferencial. Autoria própria, 2015.

A proposta desse estudo caminha em consonância ao que vem ocorrendo no Brasil e no mundo e, quanto à formatação dos painéis, seguem algumas das premissas encontradas, principalmente, em Vasconcelos (1998), Murta; Albano (2002), Projeto Doces Matas (2002), Mansur e Nascimento (2007), Vasquez (2010), Fonseca (2010) e Pacheco (2012):

i) Cores: o clima local é o Tropical de Altitude Mesotérmico com inverno frio a seco e verão chuvoso e, nesse caso, os tons mais indicados são os de vermelho e amarelo. Em locais expostos ao sol, como no Pico do Pião, Cachoeira dos Macacos e Prainha, os painéis devem ter fundo escuro e letras claras, já na Gruta dos Coelhos, local mais sombreado, letra escura sobre um fundo claro.

ii) Formato: painéis interpretativos podem ser dispostos na forma de mesa de leitura (inclinação de $60^{\circ}$ para trás) ou na posição vertical. O painel Pico do Pião deve ser no formato de mesa de leitura, por se tratar de um local com 
vista panorâmica, já nos demais pontos interpretativos podem ser colocados verticalmente, ao lado dos geossítios, sem; porém, atrapalhar a visão de outros aspectos. O tamanho ideal para os painéis é de 110 × 85 $\mathrm{cm}$.

iii) Materiais: podem ser utilizados na confecção de placas: madeira, ferro galvanizado e alumínio, fibra de vidro, aço inox, cerâmica e acrílico. Sua escolha depende de fatores variados como condições climáticas, durabilidade, estética e custo, ficando a cargo da gerência do parque, responsável por sua confecção, colocação e manutenção.

iv) Texto: deve ser alinhado à esquerda, com espaço entrelinhas e a fonte usada foi a Garamond. É necessário padronizar o tamanho da fonte nos painéis, sugere-se: títulos (tamanho 60), textos (tamanho 50 com espaço entre os parágrafos de 20), legenda explicativa (tamanho variando de 28 a 36) e fonte das imagens (tamanho 24).

v) Elaboração do texto: os textos devem ter mensagens curtas e com imagens explicativas dos conceitos abordados. Sugere-se o uso de títulos atrativos a partir de trechos de duas letras de música: Minas não tem mar (Cesar Menotti \& Fabiano) para o Geossítio Cachoeira dos Macacos (São tantas cachoeiras que nem faz falta o mar), Geossítio Pico do Pião (Além do horizonte tem um belo vale pra gente olhar) e Geossítio Prainha (Minas não tem mar, mas tem praias) e a música, A casa (Vinícius de Moraes), para o Geossítio Gruta dos Coelhos (Era uma casa muito engraçada).

vi) Uso de imagens: é recomendado o uso apenas de $50 \%$ de texto, o restante do espaço deve ser empregado na colocação de imagens. Em todos os painéis faz-se necessário a colocação de mapas com a distribuição dos geossítios do parque, bem como da localização do turista. Em alguns painéis podem ser incorporados perfis topográficos, induzindo $o$ turista a reconhecer o desnível topográfico local e associar com as condições naturais encontradas. Esquemas explicativos e fotos do parque também devem ser inseridos no intuito de aguçar a curiosidade dos turistas em conhecer aqueles locais, bem como facilitar o entendimento de determinados conceitos empregados.

$\mathrm{Na}$ figura 8 é apresentado um modelo de painel interpretativo com base nas orientações propostas. 
Figura 8: Modelo de um painel interpretativo para o Geossítio Cachoeira dos Macacos (tema queda d'água)

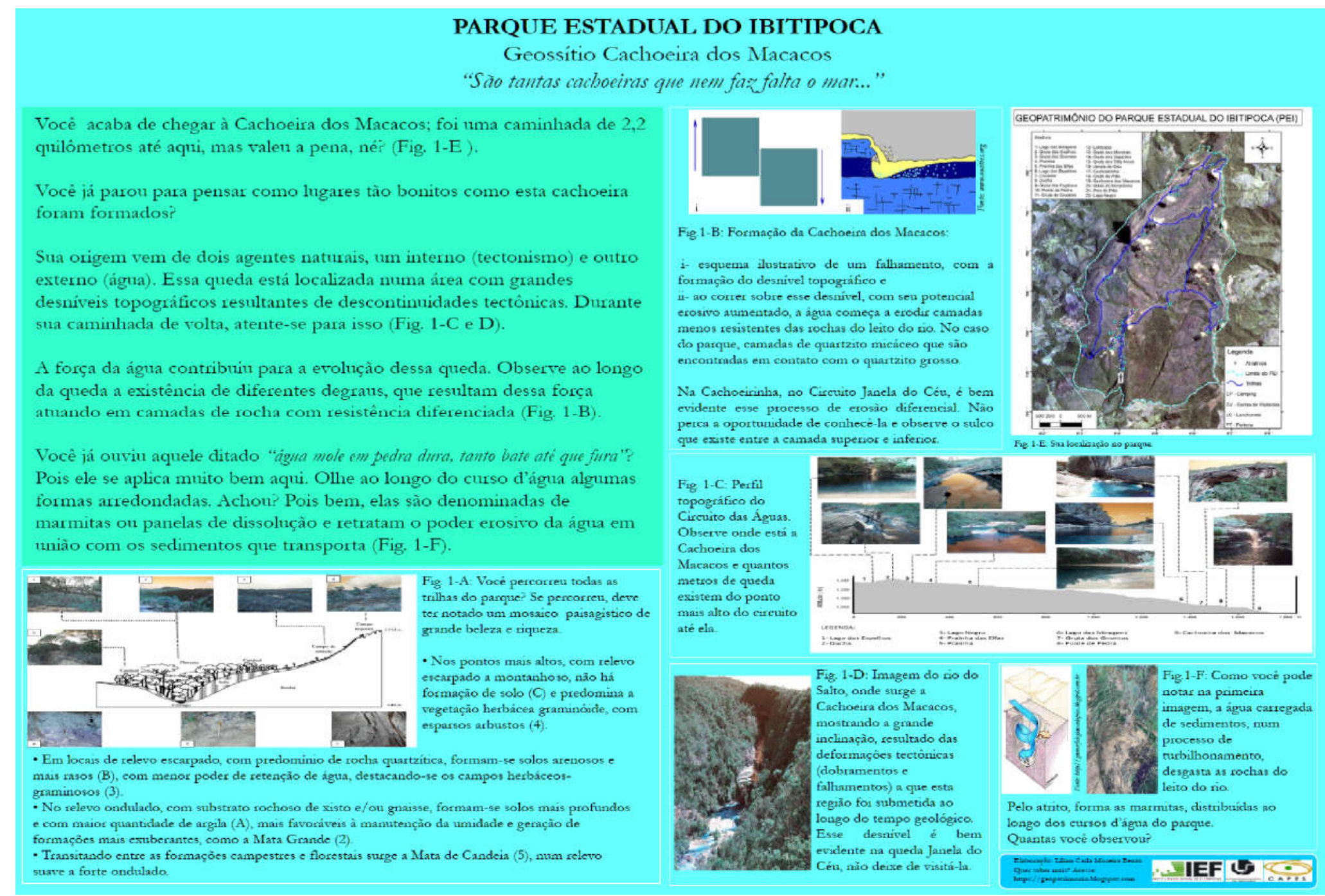

Fonte: Bento, 2014, p. 184. 


\section{CONSIDERAÇÕES E RECOMENDAÇÕES}

O objetivo desse estudo foi apresentar algumas orientações para a proposição de painéis interpretativos para o Parque Estadual do Ibitipoca, visando preencher uma lacuna do ponto de vista do conhecimento do seu geopatrimônio, oportunizando sua valorização e divulgação a partir de quatro eixos temáticos: cavernas, praias, quedas d'água e mirantes/áreas panorâmicas.

Existem diferentes tipos de meios interpretativos e para a área de estudo optou-se pelos painéis, entretanto, dada à heterogeneidade dos visitantes do parque recomenda-se que, no futuro, sejam somados outros meios, tais como folhetos que apresentam informações mais detalhadas, bem como a presença de guias capacitados a abordarem essa temática do geopatrimônio. No caso dos guias, essa é, inclusive, uma orientação do Ministério do Meio Ambiente, segundo o qual é necessário capacitá-los, haja vista estes profissionais desempenharem um importante papel na experiência do visitante, possibilitando um incremento educativo e interpretativo durante a visita (MMA, 2006).

Sobre a importância da interpretação ambiental, Bertonatti $(2005$, p. 3) traz considerações relevantes sobre seus efeitos nos turistas, segundo ele "[...] si lograrmos motivarlo, el miesmo turista se ocupará de buscar más información, de comprarse um livro, de iniciar uma búsqueda em Internet o de regresar por más. Em definitiva, se pretende que el turista sea el protagonista del viaje, no um espectador". Que a proposição dessas orientações e futura confecção dos painéis pelos gestores do parque vá ao encontro da citação acima, cultivando a curiosidade, o interesse e o respeito dos visitantes pelo geopatrimônio do PEI.

Relevante ressaltar que os objetivos de conhecimento e de afetividade citados no plano interpretativo podem induzir na conduta dos visitantes, influenciando suas atitudes no parque. Se essa conduta será ampliada para além dos limites do PEI não é possível saber, o importante, segundo Ham (2007), é que, através de mensagens interpretativas criativas, impactantes e significativas, esses visitantes se sintam estimulados a adotar atitudes positivas não apenas no local que estão visitando, mas para o seu cotidiano.

Espera-se, por fim, que este estudo possa estimular e contribuir com outras pesquisas voltadas a interpretação ambiental do geopatrimônio, uma vez que essa temática ainda carece de mais atenção, havendo poucos trabalhos na área, o que dificulta ainda mais a sua execução.

\section{AGRADECIMENTOS}

Agradecimentos à Coordenação de Aperfeiçoamento de Pessoal de Nível Superior (CAPES) pela bolsa de doutorado e ao Instituto Estadual de Florestas (IEF) pelo apoio à pesquisa.

\section{REFERÊNCIAS}

BENTO, L. C. M. PARQUE ESTADUAL DO IBITIPOCA/MG: potencial geoturístico e proposta de leitura do seu geopatrimônio por meio da interpretação ambiental. 2014. 
185 f. Tese (Doutorado em Geografia) - Instituto de Geografia, Universidade Federal de Uberlândia, Uberlândia, 2014.

BENTO, L. C. M.; RODRIGUES, S. C. Seleção de pontos interpretativos do geopatrimônio do Parque Estadual do Ibitipoca/MG (PEI): Uma proposta a partir de metodologias de avaliação numérica. Investigaciones Geográficas, México. (No prelo).

BERTONATTI, C. Interpretación y turismo: nos interes dejar um mensaje al turista? Boletín de Interpretación, Espanha, n. 12, p. 2-4, jan. 2005.

BRILHA, J. Patrimônio geológico e geoconservação - a conservação da natureza na sua vertente geológica. Braga: Palimage, 2005.

COSTA, V. C. da. Propostas de manejo e planejamento ambiental de trilhas ecoturísticas: um estudo no Maciço da Pedra Branca - Município do Rio de Janeiro (RJ). 2006. 325 f. Tese (Doutorado em Geografia) - Centro de Ciências Matemáticas e da Natureza, Universidade Federal do Rio de Janeiro, Rio de Janeiro, 2006.

DELGADO, J. A interpretação ambiental como instrumento para o ecoturismo. In: SERRANO, C. (Org.). A educação pelas pedras - ecoturismo e educação ambiental. São Paulo: Chronos, 2000. p. 155-169.

DIAS, G. et al. Contribuição para a valorização e divulgação do patrimônio geológico com recurso a painéis interpretativos: exemplos em áreas protegidas do NE de Portugal. Ciências da Terra, Lisboa, p. 132-135, 2003, n. especial. 1 CD-ROM.

FARIA, H. H. de; PIRES, A. S. Atualidades em gestão de unidades de conservação. In: ORTH, D.; DEBETIR, E. (Orgs.). Unidades de conservação - gestão e conflitos. Florianópolis: Insular, 2007. P. 11-41.

FOLMANN, A. C.; PINTO, M. L. C.; GUIMARÃES, G. B. Trilhas interpretativas como instrumentos de geoturismo e geoconservação: caso da Trilha do Salto São Jorge, Campos Gerais do Paraná. GeoURRJ, Rio de Janeiro, v. 2, n. 21, p. 239-267, 2010.

FONSECA, C. de O. Faces de paisagem: interpretação para valorização do geoturismo no Parque Estadual Serra do Rola Moça - MG. 2010. 83 f. Trabalho de conclusão de curso (Bacharelado em Turismo) - Universidade Federal de Minas Gerais, Belo Horizonte, 2010.

FORTE, J. P. Património geomorfológico da Unidade Territorial de Alvaiazére: inventariação, avaliação e valorização. 2008. 295 f. Dissertação (Mestrado em Geografia) - Faculdade de Letras, Universidade de Lisboa, Lisboa, 2008. Disponível em: <http://www.repositorium.ul.pt>. Acesso em: 05 jan. 2010.

GIACOMO, V. Z. Interpretação como instrumento para a educação patrimonial: Complexo Praça da Liberdade. 2006. 90 f. Monografia (Bacharelado em Turismo) Instituto de Geociências, Universidade Federal de Minas Gerais, Belo Horizonte, 2006.

GUIMARÃES, S. T. de L. Paisagens: aprendizados mediante as experiências - um ensaio sobre interpretação e valorização da paisagem. 2007. 160 f. Tese (Doutorado 
em Geografia) - Instituto de Geociências e Ciências Exatas, Universidade Estadual Paulista, Rio Claro, 2007.

GUTIÉRREZ-MARCO, J. C. Sabemos divulgar la geologia que hacemos? Boletim. R. Soc. Esp. Hist. Nat., Espanha, n. 100, p. 307-322, 2005. Disponível em: <http://www.igme.es/internet/patrimonio/publicaciones/revista/Gutierrez.Marco\%2020 05\%20-\%-20Divulgar\%geologia.pdf>. Acesso em: 23 abr. 2011.

HAM, S. H. ? Puede La interpretacion marcar uma diferencia: Respuestas a cuatro preguntas de psicologia cognitiva y Del comportamiento. Boletín del Interpretación, Espanha, n. 17, p. 10-16, oct. 2007.

. La interpretación es persuasiva cuando el tema es convicente. Boletín del Interpretación, Espanha, n. 25, p. 18-20, oct. 2011.

HOSE, T. A. The english origins of geotourism (as a vehicle for geoconservation and their relevance to current studies). Acta geographica slovenica, v. 51, n. 2, p. 343360, 2011. [mensagem pessoal]. Mensagem recebida por <liliancmb@yahoo.com.br> em 30 ago. 2012.

IKEMOTO, S. M. As trilhas interpretativas e sua relevância para promoção da conservação. Trilha do Jequitibá, Parque Estadual dos Três Picos (PETP), RJ. 2008. 121 f. Dissertação (Mestrado em Ciência Ambiental) - Instituto de Geociências, Universidade Federal Fluminense, Niterói, 2008.

IKEMOTO, S. M.; MORAES, M. G. de; COSTA, V. C. Avaliação do potencial interpretativo da trilha do Jequitibá, Parque Estadual dos Três Picos, Rio de Janeiro. Sociedade e Natureza, Uberlândia, v. 21, n. 3, p. 271-287, dez. 2009. Disponível em: <http://www.sociedadeenatureza.ig.ufu.br.pdf>. Acesso em: 3 jan. 2012.

MACHADO, A. C. A. R. Ecoturismo na Serra do Caraça: contribuições da interpretação para a conservação ambiental. 2008. 71 f. Monografia (Bacharelado em Turismo) - Instituto de Geociências, Universidade Federal de Minas Gerais, Belo Horizonte, 2008.

MANSUR, K. L. Diretrizes para geoconservação do patrimônio geológico do estado do Rio de Janeiro: o caso do Domínio Tectônico Cabo Frio. 2010. 350 f. Tese (Doutorado em Ciências) - Instituto de Geociências, Universidade Federal do Rio de Janeiro, Rio de Janeiro, 2010.

MANSUR, K. L.; NASCIMENTO, V. M. R. do. Popularización del conociemento geológico: metodologia del proyecto "Caminhos geológicos". Enseñanza de las Ciencias de la Tierra, Espanha, v. 15, a. 1, p. 77-84, 2007.

MARTINÉZ, E. D. et al. La conservación de la natureza deve incluir la geodiversidad y el patrimonio geológico como parte del patrimonio natural. Boletin de la sección del Estado Español de EUROPARC, Espanha, p. 54-60, mai. 2008. Disponível em: <http://www.igme.es/internet/patrimonio/descargas/Diaz-Martinez\%20al\%202008\%2 0-\%20BoletinEuropa25.pdf>. Acesso em: 20 abri. 2011. 
MARAGLIANO, M. G. Interpretación del patrimonio: uma experiência de conocimiento que revela significos. Bolétin de Interpretacion, Espanha, n. 22, p. 17-20, mai. 2010.

MENGHINI, F. B.; GUERRA, A. F. S. Trilhas interpretativas: caminhos para a educação ambiental. In: SEMINÁRIO DE PESQUISA EM EDUCAÇÃO DA REGIÃO SUL, 7., 2008. Itajaí. Anais... Itajaí: UNIVALI, 2008, 15 p.

MMA. Diretrizes para visitação em unidades de conservação. Brasília: MMA, 2006. 61 p. Disponível em:

<http://www.mma.gov.br/estruturas/ascon_boletins/_arquivos/livro.pdf>. Acesso em: 27 abr. 2012

MINISTÉRIO DO TURISMO. Ecoturismo: orientações básicas. 2 ed. Brasília: MT, 2010. 92 p. Disponível em: <http://www.turismo.gov.br.pdf>. Acesso em: 10 fev. 2012.

MIRANDA, J. M. La interpretación del patrimonio tiene que ver com significados. 2007. 2008. Textos de docência. Mensagem recebida por <liliancmb@yahoo.com.br> em 23 abri. 2012.

MOREIRA, J. C. Geoturismo e interpretação ambiental. Ponta Grossa: Editora da UEPG, 2011. $157 \mathrm{p}$.

Interpretação ambiental, aspectos geológicos e geomorfológicos. Boletim de Geografia, Maringá, v. 30, n. 2, p. 87-98, 2012.

.; BIGARELLA, J. J. Interpretação ambiental e geoturismo em Fernando de Noronha. In: CASTILHO, C. J. M.; VIEGAS, J. M. (Org.). Turismo e práticas socioespaciais: múltiplas abordagens e interdisciplinaridades. Recife: Editora Universitária, 2008. p. 171-191.

MURTA, S. M.; ALBANO, C. (Orgs.). Interpretar o patrimônio - um exercício do olhar. Belo Horizonte: Editora UFMG, 2002. 288 p.

.; GOODEY, B. Interpretação do patrimônio para visitantes: um quadro conceitual. In: MURTA, S. M.; ALBANO, C. (Orgs.). Intepretar o patrimônio - um exercício do olhar. Belo Horizonte: Editora UFMG, 2002. p. 13-46.

OLIVEIRA, S. C. C. de. A interpretação ambiental como instrumento de diversificação das atividades recreativas e educativas das Trilhas do Jardim Botânico Benjamim Maranhã (João Pessoa, Paraíba, Brasil). 2010. Dissertação (Mestrado em Desenvolvimento e Meio Ambiente) - [s.I], Universidade Federal da Paraíba, João Pessoa, 2010.

PACHECO, J. L. Interpretação do patrimônio geológico: uma aplicação ao Geoparque Arouca. 2012. 100 f. Dissertação (Mestrado em Patrimônio Geológico e Geoconservação) - Escola de Ciências, Universidade do Minho, Minho, 2012. 
PIEKARZ, G. F.; MANOSSO, F.; LICCARDO, A. O patrimônio geológico das unidades de conservação: geoconservação e geoturismo. In: CONGRESSO BRASILEIRO DE UNIDADES DE CONSERVAÇÃO, 6., 2009, Curitiba. Anais... Curitiba: [s.n], 2009. ñ paginado.

PROJETO DOCES MATAS. Manual de introdução à interpretação ambiental. Belo Horizonte: IEF: IBAMA: Fundação Biodiversitas, 2002. 108 p. Disponível em: $<$ http://www.ief.mg.gov.br/index.php?Hemid=58\&id=79\&option=com_conteent\&task= view>. Acesso em: 21 out. 2011.

REYNARD, E. Scientific research and tourist promotion of geomorphologica heritage. Geogr. Fis. Dinam. Quat., v. 31, p. 225-230, 2008. [mensagem pessoal]. Mensagem recebida por<liliancmb@yahoo.com.br> em 30 ago. 2012.

ROBINSON, E. Tourism in geological landscapes. Geology today, p. 151-153, jul./aug. 1998. [mensagem pessoal]. Mensagem recebida por

<liliancmb@yahoo.com.br> em 30 ago. 2012.

RODRIGUES, J. de C. Geoturismo - uma abordagem emergente. In: CARVALHO, C. N. de; JACINTO, A. (Edits.). Geoturismo \& desenvolvimento local. Idanha-aNova: [s.I], 2008. p. 38-58.

RODRIGUES, J.; CARVALHO, C. N. de. Geotourist Trails in Naturtejo the Geopark. In: JACINTO, A. et al. (Orgs.). New ChalleNges with geotourism - Proceedings of the VIII European Geoparks Conference. Portugal: [s.I], 2009. p. 45-50.

SILVA, F. R. G. et al. Guia didático para os intérpretes/educadores da 'Trilha do Lobo', da Fundação Zoo-botânica de Belo Horizonte-MG. Revista da Biologia e Ciências da terra, [s.I], v. 6, n. 2, p. 286-294, 2 sem. 2006. Disponível em:

<http://educep.uepb.edu.br/rbct/sumarios/pdf/trilhadidatica.pdf>. Acesso em: $10 \mathrm{dez}$. 2011.

SIMIQUELI, R. F. Perspectivas para a conservação do Parque Estadual do Ibitipoca-MG: participação social, avaliação, manejo e percepção ambiental. 2008. 158 f. Dissertação (Mestrado em Ecologia) - Instituto de Ciências Biológicas, Universidade Federal de Juiz de Fora, Juiz de Fora, 2008.

TILDEN, F. Interpreting Our Heritage. EUA: University of North Carolina Press, 1957. $191 \mathrm{p}$.

URQUÍ, L. C.; MARTINEZ, J. L.; VALSERO, J. J. D. (Ed.). Patrimonio geológico y geodiversidad: investigación, gestión y relación con lós espacios naturales protegidos. Madrid: Instituto Geológico y Minero de España, 2007. 360 p.

VASCONCELOS, J. M. de O. Avaliação da visitação pública e da eficiência de diferentes tipos de trilhas interpretativas no Parque Estadual do Pico do Marumbi e Reserva Natural Salto Morato - PR. 1998. 151 f. Tese (Doutorado em Ciências Florestais) - Setor de Ciências Agrárias, Universidade Federal do Paraná, Curitiba, 1998. 
VASQUEZ, L. M. de J. Estratégia de valorização de geossítios no Geoparque Arouca. 2010. 393 f. Dissertação (Mestrado em Patrimônio Geológico e geoconservação), Escola de Ciências, Universidade do Minho, Braga, 2010.

VERDECCHIA, A. Qué quieren lós visitantes y cómo podemos averiguarlo. Boletín del Interpretación, Espanha, n. 9, p. 7-8, agos. 2003. 